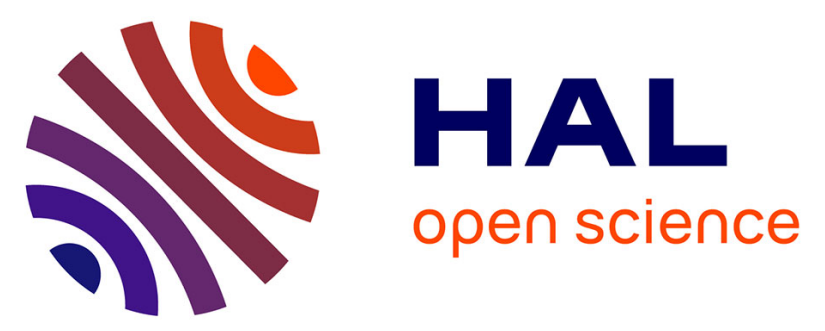

\title{
High-Resolution Imaging of Retinal Vasculitis by Flood Illumination Adaptive Optics Ophthalmoscopy: A Follow-up Study
}

Marie-Hélène Errera, Marthe Laguarrigue, Florence Rossant, Edouard Koch, Céline Chaumette, Christine Fardeau, Mark Westcott, José-Alain Sahel, Bahram Bodaghi, Jonathan Benesty, et al.

\section{To cite this version:}

Marie-Hélène Errera, Marthe Laguarrigue, Florence Rossant, Edouard Koch, Céline Chaumette, et al.. High-Resolution Imaging of Retinal Vasculitis by Flood Illumination Adaptive Optics Ophthalmoscopy: A Follow-up Study. Ocular Immunology and Inflammation, 2019, pp.1-10. 10.1080/09273948.2019.1646773 . hal-02426467

\section{HAL Id: hal-02426467 https://hal.sorbonne-universite.fr/hal-02426467}

Submitted on 2 Jan 2020

HAL is a multi-disciplinary open access archive for the deposit and dissemination of scientific research documents, whether they are published or not. The documents may come from teaching and research institutions in France or abroad, or from public or private research centers.
L'archive ouverte pluridisciplinaire HAL, est destinée au dépôt et à la diffusion de documents scientifiques de niveau recherche, publiés ou non, émanant des établissements d'enseignement et de recherche français ou étrangers, des laboratoires publics ou privés. 


\section{High resolution imaging of retinal vasculitis by flood illumination adaptive optics ophthalmoscopy: a follow-up study}

Marie-Hélène Errera ${ }^{1,2}$, Marthe Laguarrigue ${ }^{3}$, Florence Rossant ${ }^{3}$, Edouard Koch $^{1}$, Céline Chaumette $^{1}$, Christine Fardeau, ${ }^{4}$ Mark Westcott, ${ }^{5}$ José-Alain Sahel ${ }^{1,2}$, Bahram Bodaghi ${ }^{2,4}$, Jonathan Benesty ${ }^{1,2}$, Michel Paques ${ }^{1,2}$

${ }^{1}$ Quinze-Vingts hospital, INSERM-DHOS CIC 1423, Paris, F-75012 France, Sorbonne Universités, UPMC Univ Paris 06, France

${ }^{2} \mathrm{DHU}$ ViewRestore

${ }^{3}$ Institut Supérieur d'Electronique de Paris, 75006 Paris, France

${ }^{4}$ Ophthalmology department, Pitié-Salpêtrière Hospital, Sorbonne Universités, UPMC Univ Paris 06, France

${ }^{5}$ Department of Medical Retina, Moorfields Eye Hospital, NHS Foundation Trust, Biomedical Research Centre, UCL Institute of Ophthalmology, London, UK.

Key words: retina, vasculitis, flood-illumination adaptive optics ophthalmoscopy.

Corresponding author: Marie-Hélène Errera, errera.mhelene@gmail.com

Funding details : Supported by the Institut National de la Santé et de la Recherche Médicale (Contrat d'Interface 2011) and the Agence Nationale de la Recherche (ANR-09TECS-009 and ANR-12-TECS-0015-03). The funding organizations had no role in the design or conduct of this research.

Disclosure of interest: Professor Michel Paques is consultant for Imagine Eyes. 
Purpose: To monitor perivascular sheathing during the course of retinal vasculitis by flood illumination adaptive optics ophthalmoscopy (AOO).

Methods: Perivenous sheathing and venous diameters were quantitatively analyzed by semi-automatic segmentation of AOO images in 12 eyes of treatment-naive patients with retinal vasculitis.

Results: The width of venous sheathing ranged from 45 to $225 \mu \mathrm{m}$ (mean $101.0 \mu \mathrm{m} \pm$ 54.3). In 10 cases, the underlying vein showed focal narrowing (mean \pm SD $14 \% \pm 10$ ). Focal narrowing of arteries was also present in one eye. At presentation, width of sheathing and vessel diameters were not correlated with fluorescein leakage. During follow-up, 5 eyes showed an increase in vein diameter or resolution of narrowing and in 10 eyes a thinning of vascular sheathing was observed $(p=0.003)$.

Conclusions: Perivenous sheathing may be quantitatively analyzed and monitored by AOO. AOO may therefore contribute to monitor vascular sheathing during posterior uveitis.

Key-words: adaptive optics, posterior uveitis, retina, uveitis, retinal vasculitis 
Retinal vasculitis may occur either as isolated or in association with various inflammatory diseases affecting the eye. ${ }^{1}$ Ophthalmoscopic presentations of retinal vasculitis combine vascular sheathing and focal fluorescein leakage. It affects more frequently veins than arteries. It may be associated with inflammatory diseases involving the central nervous system, most notably Behcet's disease, sarcoidosis, systemic lupus erythematosus ('vasoocclusive retinopathy') or multiple sclerosis.

Retinal vasculitis may lead to severe visual loss, either because of the complications of vascular obstruction which can lead to capillary non perfusion and development of pre-retinal new vessels and/or tractional detachment, or macular edema due to blood-retinal barrier rupture. Much remains to be known about the clinical and pathologic features of retinal vasculitis and the mechanisms leading to visual loss. In experimental retinal vasculitis, paravascular cellular infiltrates consist of a variable association of macrophages, $T$ cells and CD45+ leucocytes. ${ }^{2}$ They may co-localize with areas of leakage on fluorescein angiography $(F A)^{3,4}$ suggesting a causal relationship. In humans, segmental perivenous lymphoplasmocytic infiltration has been documented in Behcet's disease, multiple sclerosis and idiopathic retinal vasculitis. ${ }^{5-9}$ However, the specific mediators involved in perivascular infiltration remain elusive and a detailed time-course of vascular infiltrates has not been reported.

Given the diagnostic and prognostic value of retinal perivascular sheathing, it would be of clinical interest to better identify, quantify and monitor retinal vasculitis. In experimental uveitis, grading systems based on fundus imaging ${ }^{2}$ or optical coherence tomography (OCT $)^{3}$ have been proposed but have not been applied yet in humans. As a result, there is no validated procedure for the grading of human vasculitis.

Adaptive optics is an optoelectronic technology which improves the lateral resolution of fundus images, allowing quantitative analysis of microvascular structures. ${ }^{10,11}$ We recently reported that flood-illumination adaptive optics (AOO) imaging allows highly sensitive detection of paravascular infiltration characteristic of retinal vasculitis. ${ }^{12} \mathrm{By} \mathrm{AOO}$, vascular sheathing appears as fusiform or linear opacities on both sides of vessels, often co-localizing with focal vascular narrowing. We also reported a case of regression of sheathing under therapy, suggesting that AOO may be useful for monitoring treatment. ${ }^{12}$ Here, we quantified the extent of vascular sheathing and monitored its evolution using a semi-automated segmentation software. Our objective was to quantitatively explore the changes over time of vasculitis.

\section{Material and Methods}

This retrospective study adhered to the tenets set forth in the Declaration of Helsinki, and approval of the local Ethics Committee (St Antoine hospital, Paris, France) was obtained. 
Inclusion was proposed to treatment-naive patients with retinal vasculitis of different etiologies and idiopathic and clear ocular media. Retinal vasculitis was identified by the presence of typical vascular sheathing and/or by foci of fluorescein leakage. All cases were reviewed by a senior uveitis specialist (MHE). Each subject received full oral and written information and gave consent prior to inclusion. Part of the data from two patients (cases 6 and 9 ) has been previously reported. ${ }^{10}$ Follow-up was customized according to each case's needs.

Color fundus photographs, scanning laser ophthalmoscopy and FA were performed at the Quinze-Vingts Hospital using standard procedures. AOO imaging was done with a commercially available AOO camera ( $\mathrm{rtx} 1^{\mathrm{TM}}$ camera; Imagine Eyes, Orsay, France; illumination wavelength $850 \mathrm{~nm}$; field of view $4^{\circ} \times 4^{\circ}$ ) using a previously described procedure. ${ }^{10}$ Briefly, en face AOO fundus images were obtained through dilated pupils (1\% tropicamide; Novartis, France). Because of the asymmetric configuration of the camera, only the right eye could undergo such exploration. An external target guiding the fellow eye allowed navigating along large vessels up to approximately $25^{\circ}$ from the disc. Retinal vessels (veins and arteries) up to $25^{\circ}$ from the disc were screened by AOO. No photographs of the macula were obtained. Perivascular cuffs were systematically searched for by moving the external target in order to navigate along the temporal vessels. When a vascular abnormality was identified on the live fundus display, a stack of images (40 images in 2 seconds) was acquired and automatically processed using the built-in software of the AOO camera (AO image 2.0). On average, one to three averaged images per minute could be taken.

Selected images were automatically segmented using a custom software running under Matlab (Mathworks, Natick, Massachussetts, USA) ${ }^{13}$ Briefly, after detection of the axial reflex of vessels, the external and internal walls of the perivascular cuff were simultaneously detected using an original tracking procedure to cope with deformation along vessels. Then, their positioning was refined using a deformable model embedding a parallelism constraint in order to control the distance of the curves to their reference line and improve the robustness to image noise. ${ }^{13}$ From this segmentation, the lumen and the sum of the width of the perivascular sheathing on both sides were extracted along a vascular segment up to $1000 \mu \mathrm{m}$ long (Fig 1). At sites of vascular narrowing, the relative narrowing was calculated as the ratio of minimal diameter over the average of upstream and downstream diameters. The whole procedure was done under human supervision; inadequate segmentations were discarded.

Results

We reviewed twenty cases of uveitis with retinal vasculitis seen in our department who underwent AOO imaging between June 2014 and March 2016. Images were then examined by three of us (JB, MHE and MP). The presence of perivascular sheathing was assessed. 
Images showing acceptable contrast were selected for morphometric analysis. Nine cases were rejected because of a poor contrast of vascular sheathing. Twelve eyes of 12 consecutive subjects ( 8 women, 4 men; mean age, 42 years) were included in final evaluation. Diagnoses included birdshot chorioretinopathy $(n=3)$, toxoplasmic retinochoroiditis $(n=2)$, ocular tuberculosis $(n=2), M S$, idiopathic retinal vasculitis, aneurysm and neuroretinitis (IRVAN), ocular Lyme borreliosis, syphilitic chorioretinitis and idiopathic retinal vasculitis (one case each). Their mean duration of visual symptoms was 7.8 months (range, 1-20) and the mean follow-up was 6.5 months $( \pm 5.6)$. None was treated by antiinflammatory treatment at time of first examination in our department. Their clinical characteristics are summarized in Table 1.

Mean $( \pm S D)$ width of perivascular opacification was $101.0( \pm 54.3) \mu \mathrm{m}$. The length of perivascular opacification ranged from $250 \mu \mathrm{m}$ to several millimeters. At sites of sheathing, focal narrowing of veins was observed in 10 eyes; the degree of venous narrowing relative to adjacent areas ranged from 4 to 28\% (mean, 14\%) in 10 eyes. Focal narrowing of arteries was also present in one eye (25\% of narrowing) diagnosed with idiopathic retinal vasculitis and arterial dilatation at the site of macroaneurysm in the IRVAN case. Examples of perivascular opacification and vein narrowing imaged by AOO is shown in Fig 2. Representative examples of segmented AOO images are shown in Fig 3.

More than one area of sheathing was observed in 6 eyes. A relationship was found between leakage of vessels on fluorescein angiography and vascular sheathing of the same area on AOO in 8 out of 12 eyes (66\%). Seven eyes (58\%) showed perivenous sheathing in additional areas with no detectable abnormalities on fundus photographs or on FA (Fig 4). On the opposite, all areas showing fluorescein leakage showed perivascular sheathing (Figs 5 and 6).

Corticosteroid treatment was initiated in ten patients. Four were also treated with immunomodulator agents and six received specific antibiotic treatment. Patient 8 , which had IRVAN, was not treated. Intervals between follow-up exams varied according to the treatment regimen, clinical evolution and availability of the patient. The range of intervals between AOO imaging sessions varied between 2 weeks and 2 years (median, 2.5 months). Clinical evolution showed a progressive resolution of inflammatory signs in all but two cases (cases with IRVAN and ocular Lyme borreliosis). At last examination, on average the thinning had decreased from $101.0 \mu \mathrm{m} \pm 54.3$ to $23.6 \mu \mathrm{m} \pm 15.5(p=0.003)$. Two eyes showed persistent venous sheathing at last examination. No vein occlusion occurred. Recurrence of perivenous sheathing was observed in 4 cases (example in Fig 6). These recurrences occurred at the same site as the initial one. 
Changes of vessel diameters did not show a clear correlation with the overall level of ocular inflammation. Among the 10 eyes with focal vascular narrowing at presentation, 5 eyes showed an increase in vein diameter. Figure 7 shows morphograms of the long-term evolution of perivenous sheathing and venous diameters.

In an attempt to clarify the relationship between vascular sheathing and venous narrowing, we analyzed a subgroup of four eyes that had monthly AOO imaging. This showed a regular decrease of perivenous sheathing in all cases, which contrasted with the apparent stability of the diameter of the underlying veins (Fig 8). Note that none of these cases showed venous narrowing initially. However, in another subgroup of 5 eyes, it could be seen that the reduction of perivascular sheathing was accompanied by displacement of adjacent nerve fiber bundles (figure 9 and supplementary figures- videos), suggesting that expansion of perivenous infiltration displaced adjacent nerve fiber bundles (cases 1,3,7,8,9 and 11).

In areas of sheathing showing breakdown of the blood-retinal barrier, it could be observed that resolution of the fluorescein leakage occurred with the disappearance of sheathing (figure 3b).

Periarterial sheathing was present in two eyes (cases 8 and 11). One of them showed also focal reduction of diameter (figure 5). During follow-up, patient 8 (IRVAN syndrome) showed enlargement of the macroaneurysm but no change in the width of periarterial sheathing (figure 10). Although, patient 11 (idiopathic vasculitis) showed a disappearance of perivascular opacification and of vessels narrowing (figure 5).

\section{Discussion}

We show here that thanks to its capabilities to document at a microscopic level both the width of perivascular sheathing and the vascular narrowing, AOO brings new opportunities for the evaluation of retinal vasculitis. This may not only reveal the severity of the disease but also indicate the risk of local complications. Albeit AOO imaging is of limited interest in case of media opacities such as vitritis, it offers the unique possibility to detail fine features of paravascular opacities. We demonstrated for instance that IRVAN was associated with perivenous opacities. We also observed in many cases the presence of arteriolar narrowing associated with arteritis. The contrast was highly variable between the infiltrate and the surrounding retina, which may be due to the specific nature of the infiltrate or to the background pigmentation. Infiltrates associated with blood-retinal barrier rupture were more often located along the major vessels of the temporal arcades in an area within $10^{\circ}$ from the optic disc. We also documented here the time-course of resolution of sheathing, showing that the width of the sheathing was halved in three months for one patient who underwent serial 
AOO imaging. Recurrence was often observed in the same site as initially, suggesting that cell infiltrates do not occur randomly but that there are preferential sites. Recently, using another software, Mahendradas et al, have also shown a complete resolution of the sheathing by $\mathrm{AO}$ on follow-up. ${ }^{14}$

Venous narrowing and occlusion are common complications of vasculitis. By AOO imaging, minute venous narrowing could be documented. For few patients, there was a limited yet clear correlation between the width of sheathing and venous narrowing. The mechanisms of vascular occlusion during vasculitis are uncertain. Pathologic studies have suggested a thrombotic or obliterative mechanism. ${ }^{7}$ In our patients, morphometric analyzes showed that in most eyes venous narrowing temporally and spatially correlate with the width of the perivascular cuff. Furthermore, in 5 cases, it could be documented that adjacent inner retinal structures were displaced by the perivascular cuffs rather than infiltrated. This strongly suggests that local compression by the infiltrate itself may contribute to vascular occlusions. This suggests that there is compression rather than infiltration. This was not observed in all eye, hence one should be cautious about such interpretation. Relationship with blood-retinal barrier also remains uncertain.

Periarterial infiltrates are rare. We documented here two cases with periarteritis, one case of IRVAN syndrome and one case of idiopathic vasculitis. The arteriolar wall remained visible through the infiltration, suggesting that the infiltrate was extra-parietal. AOO imaging demonstrated a similar appearance of both periarterial infiltrates and perivenous infiltrates, i.e, perivascular opacifications. There was also a reduction of arteriolar caliber.

There are some limits to our study. It is unable to image the retina in presence of vitreous haze or edema surrounding the vessel. It is significant to note that vitreous haze, retinal edema and/or cataract limited AOO fundus imaging in 8 eyes among the twenty cases initially selected.

AOO imaging cannot provide images of the peripheral vessels more than $25^{\circ}$ away from the disc. It is also uncertain to which extent the foci that were measured actually are representative of the whole inflammatory process. Our sample size was too small to differentiate the effect of the various anti-inflammatory drugs.

The possibility to monitor vascular inflammation offers interesting fundamental and clinical perspectives. For instance, our data suggest that perivascular infiltrates may contribute to venous occlusion through a compressive effect. The effect of therapy can be quantitatively evaluated. Additional studies are needed to further assess the correlation between clinical severity and AOO features and to document the time-course of sheathing. Those will be helpful in determining the relationship between narrowing and obstruction, between sheathing and blood-retinal barrier rupture, and between $\mathrm{AOO}$ features and 
etiology. AOO may also be of interest for the screening of vascular inflammation in patients affected by cerebral diseases.

\section{References}

1. Rosenbaum JT, Sibley CH, Lin P. Retinal vasculitis. Curr Opin Rheumatol. 2016;28(3):228-35.

2. Copland DA, Wertheim MS, Armitage WJ, Nicholson LB, Raveney BJ, Dick AD. The clinical time-course of experimental autoimmune uveoretinitis using topical endoscopic fundal imaging with histologic and cellular infiltrate correlation. Invest Ophthalmol Vis Sci. 2008;49(12):5458-65.

3. Chu CJ, Herrmann P, Carvalho LS, et al. Assessment and in vivo scoring of murine experimental autoimmune uveoretinitis using optical coherence tomography. PLOS One. 2013;8(5):1-10.

4. Stanford MR, Graham EM, Kasp E, Brown EC, Dumonde DC, Sanders MD. Retinal vasculitis: correlation of animal and human disease. Eye. 1987;1(Pt 1):69-77.

5. Charteris DG, Champ C, Rosenthal AR, Lightman SL. Behcet's disease: activated T lymphocytes in retinal perivasculitis. $\mathrm{Br} J$ Ophthalmol. 1992;76(8):499-501.

6. George RK, Chan CC, Whitcup SM, Nussenblatt RB. Ocular immunopathology of Behcet's disease. Surv Ophthalmol. 1997;42(2):157-62.

7. Hughes EH, Dick AD. The pathology and pathogenesis of retinal vasculitis. Neuropathol Appl Neurobiol. 2003;29(4):325-40.

8. Eichenbaum JW, Friedman AH, Mamelok AE. A clinical and histopathological review of intermediate uveitis ("pars planitis"). Bull N Y Acad Med. 1988;64(2):164-74.

9. Engell $\mathrm{T}$, Jensen $\mathrm{OA}$, Klinken L. Periphlebitis retinae in multiple sclerosis. A histopathological study of two cases. Acta Ophthalmol. 1985;63(1):83-8.

10. Koch E, Rosenbaum D, Brolly A, et al. Morphometric analysis of small arteries in the human retina using adaptive optics imaging: relationship with blood pressure and focal vascular changes. J Hypertens. 2014;32(4):890-8.

11. Chui TY, Gast TJ, Burns SA. Imaging of vascular wall fine structure in the human retina using adaptive optics scanning laser ophthalmoscopy. Invest Ophthalmol Vis Sci. 2013;54(10):711524

12. Errera $\mathrm{MH}$, Coisy $\mathrm{S}$, Fardeau $\mathrm{C}$, et al. Retinal vasculitis imaging by adaptive optics. Ophthalmology. 2014;121(6):1311-1312.e2.

13. Lermé N, Rossant F, Bloch I, Paques M, Koch E, Benesty J. A fully automatic method for segmenting retinal artery walls in adaptive optics images. Pattern Recognition Letters. 2015;72:72-81 
14. Mahendradas P, Vala R, Kawali A, Akkali MC, Shetty R. Adaptive Optics Imaging in Retinal Vasculitis. Ocul Immunol Inflamm. 2018;26(5):760-766

Legends

Figure 1. Patient 8 (IRVAN syndrome). Top left, retinophotography at baseline and bottom left, fluorescein angiography showing no detectable sheathing or leakage (in squares). Middle: Segmented AOO image of periphlebitis. On the right, the morphogram shows the variations of the width of the lumen diameter and perivascular cuff.

Figure 2: Patient 3 (birdshot chorioretinopathy). Left, FA at baseline: note the fluorescein leakage in the area enclosed by the square. Right, AOO imaging showing perivenous sheathing (arrowheads) and focal narrowing (asterisk).

Figure 3: Patient 12 (presumed ocular tuberculosis). (a) FA and AOO at baseline, AOO images of periphlebitis at baseline (arrows) in area enclosed in the square showing fluorescein leakage at baseline. (b) FA and AOO at one month, $\mathrm{AOO}$ images of periphlebitis diseappearance (asterisk) in area enclosed in the square showing resolution of fluorescein leakage. Bottom, segmented AOO image. Right, morphogram showing the variations of lumen diameter (red curve) and perivascular cuff width (violet curve).

Figure 4. Patient 9 (ocular Lyme borreliosis). Top left, Retinophotography at baseline showing no detectable sheathing. Top right, FA at baseline showing no detectable fluorescein leakage in the area enclosed by the square. AOO imaging: follow-up of venous sheathing (arrowheads) and narrowing (arrows) along the superotemporal vein in a case of Lyme's disease. Note the fluctuations over time of focal narrowings (arrows).

Figure 5: Patient 11 (idiopathic retinal vasculitis). FA at baseline: diffuse leakage of veins and retinal arteries (area enclosed by the square). AOO imaging showing loss of transparency around the vein and the artery suggestive of inflammatory infiltration. The peak venous sheathing was measured at $225 \mu \mathrm{m}$ for the vein and $66 \mu \mathrm{m}$ for the artery. The maximal vascular narrowing was measured at $28 \%$ for the vein and $25 \%$ for the artery. After 3 months of oral corticosteroids, AOO imaging shows regression of perivascular infiltrates. Note also the widening of the artery. 
Figure 6. Patient 1 (birdshot retinochoroidopathy). Top: FA at baseline. The square indicates the area magnified in AOO images. Bottom: Successive AOO images. Note the fluctuations over time of perivenous sheathing (arrowheads) and of venous narrowing (asterisk). The sheathing recurred at month 24 .

Figure 7: Illustration of the changes of perivenous sheathing and venous diameters (curves in pale grey colour) between the first and last examination in patient 7. Perivenous sheathing (curves in grey colour) and venous diameters (curves in pale grey colour).

Figure 8. Short-term evolution of the width of perivenous sheathing and of venous diameters normalized to initial values in a subgroup of four eyes (cases 3,4,5 and 7). For each case, a single area was followed-up. Note that the decrease of perivenous sheathing is not correlated with venous diameter changes.

Figure 9. Patient 7. (a) FA at baseline, (b, $c$ and d) AOO images showing perivenous sheathing with and no detectable fluorescein leakage in the area of sheathing. Arrowheads in $c$ and $d$ show axons fascicles that come closer to the vein following the resolution of sheathing.

Figure 10. Case 8 (IRVAN). AOO follow-up images of periarterial sheathing (macroaneurysm). 


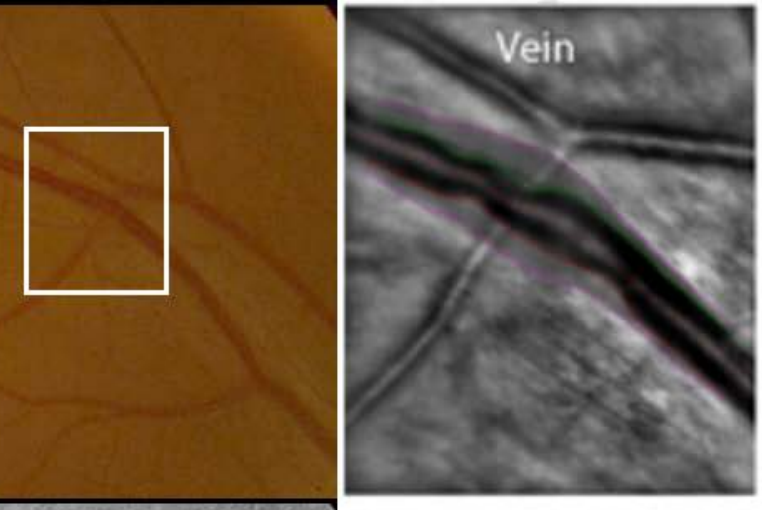

width ( $\mu \mathrm{m})$
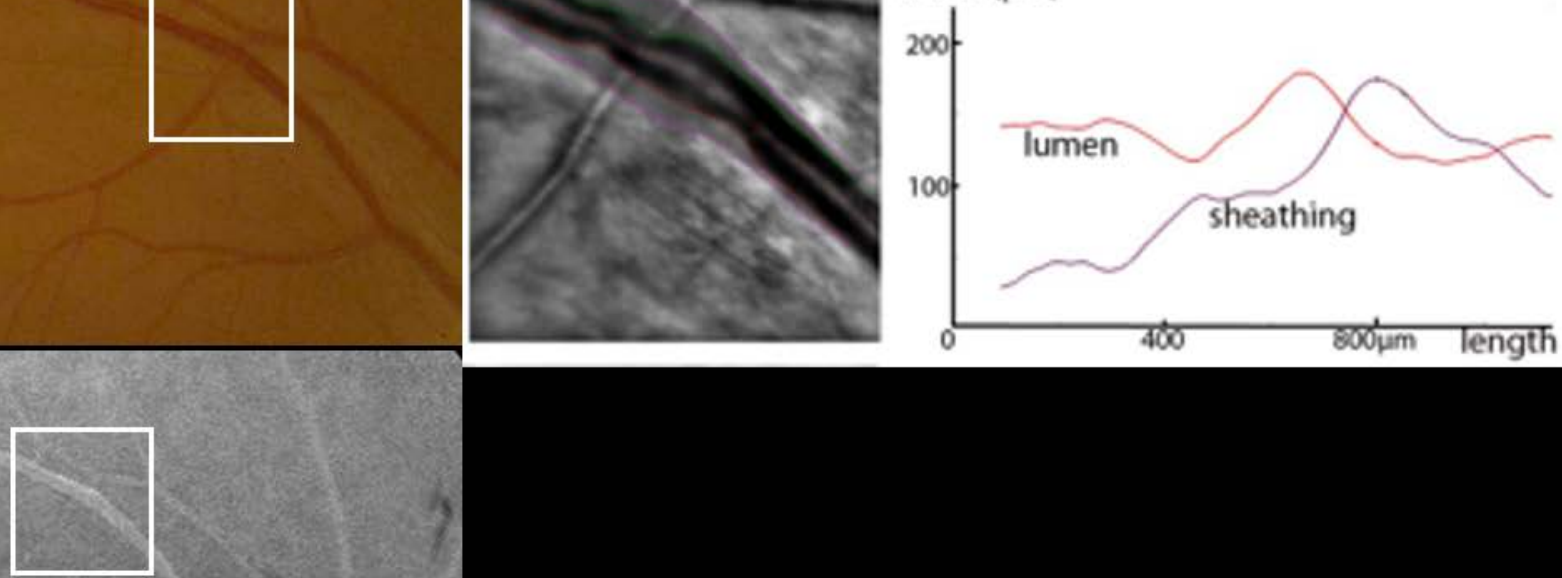


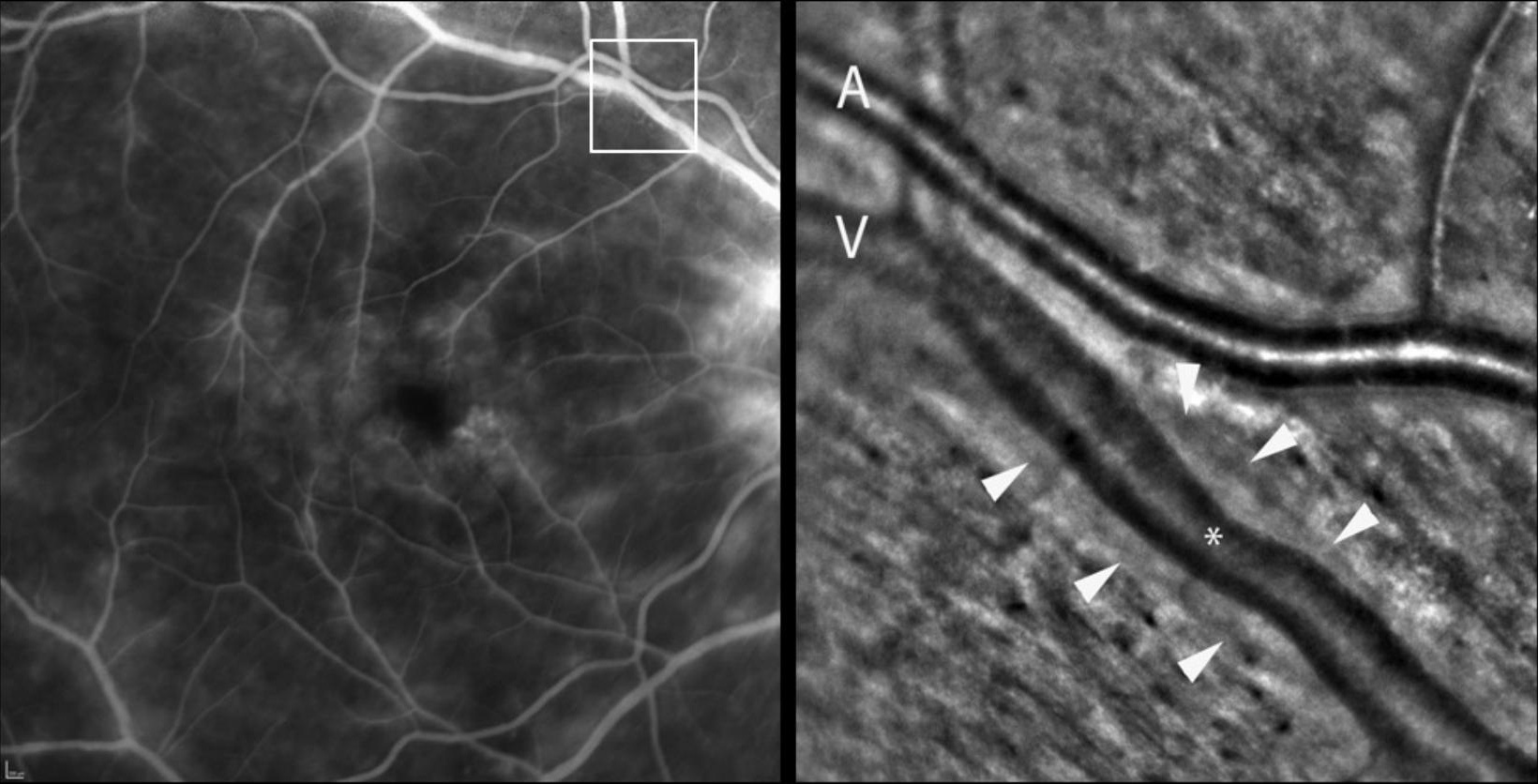



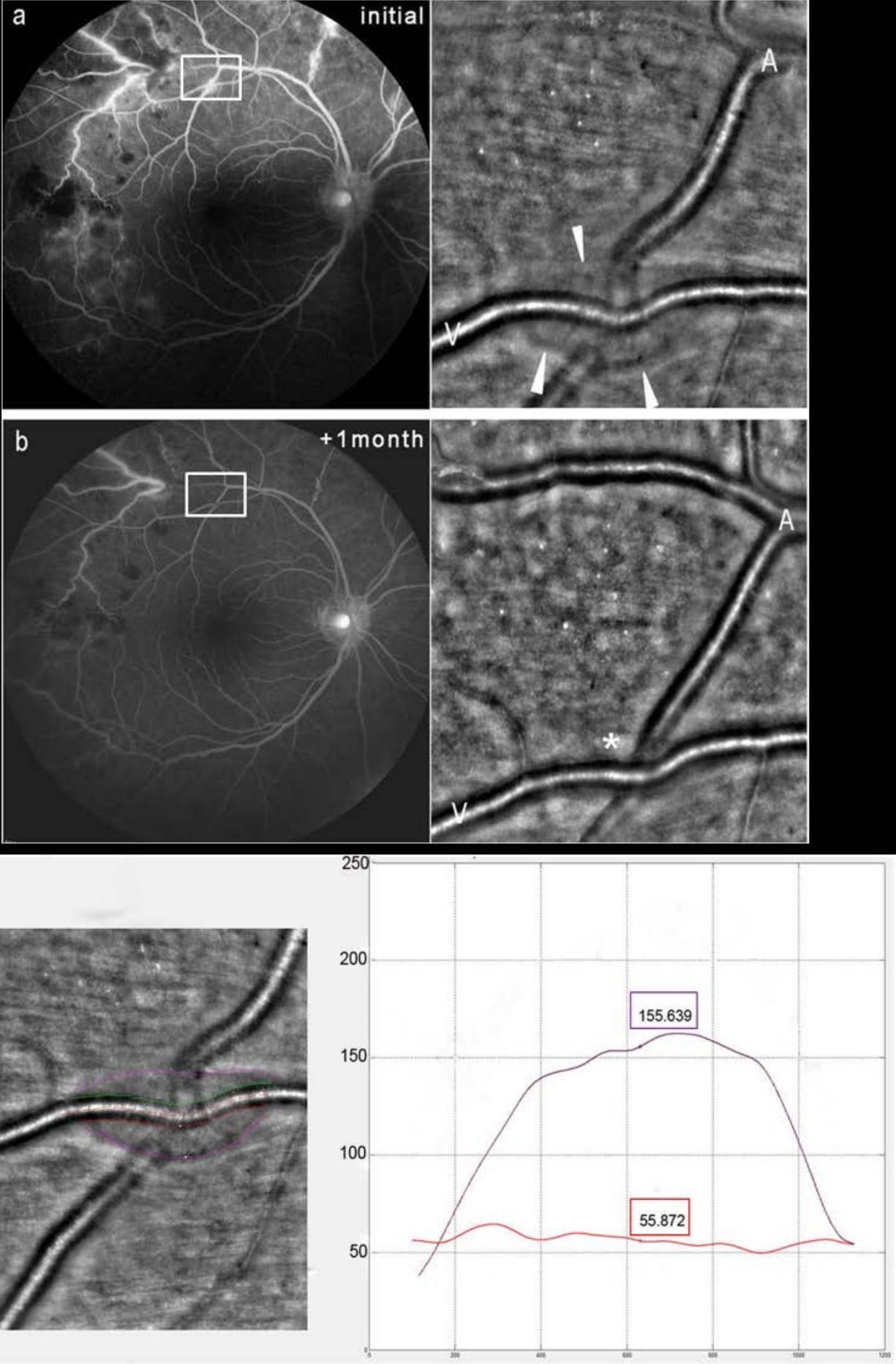

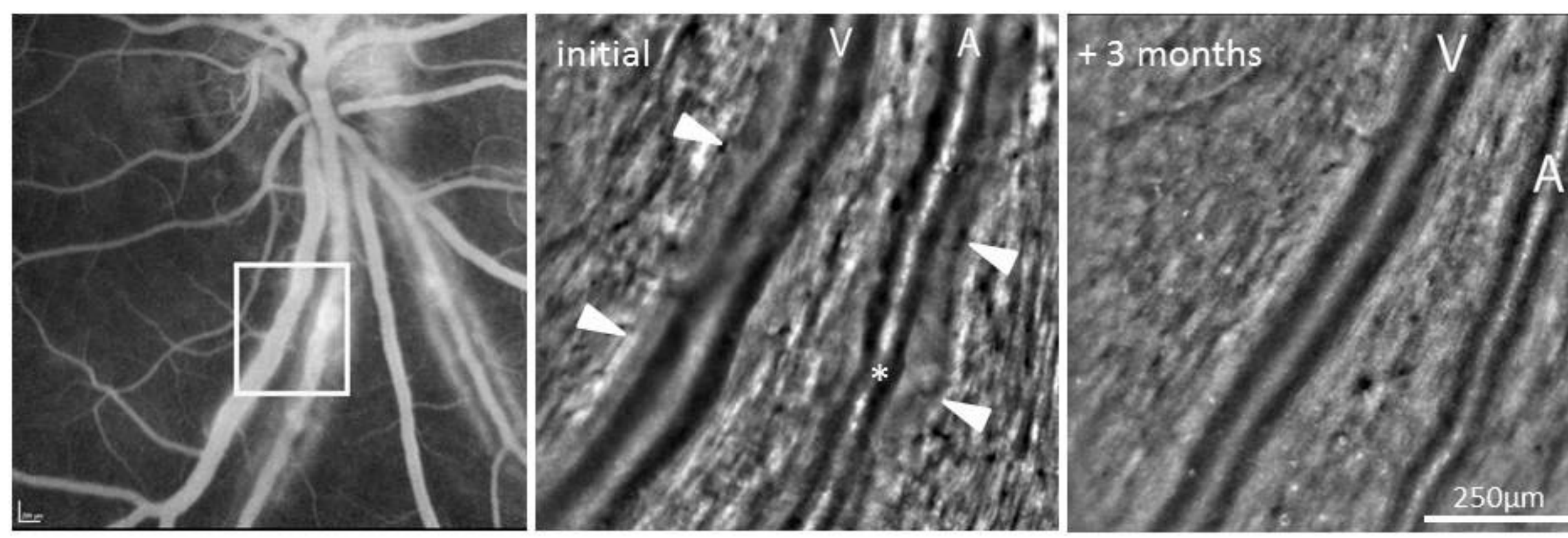


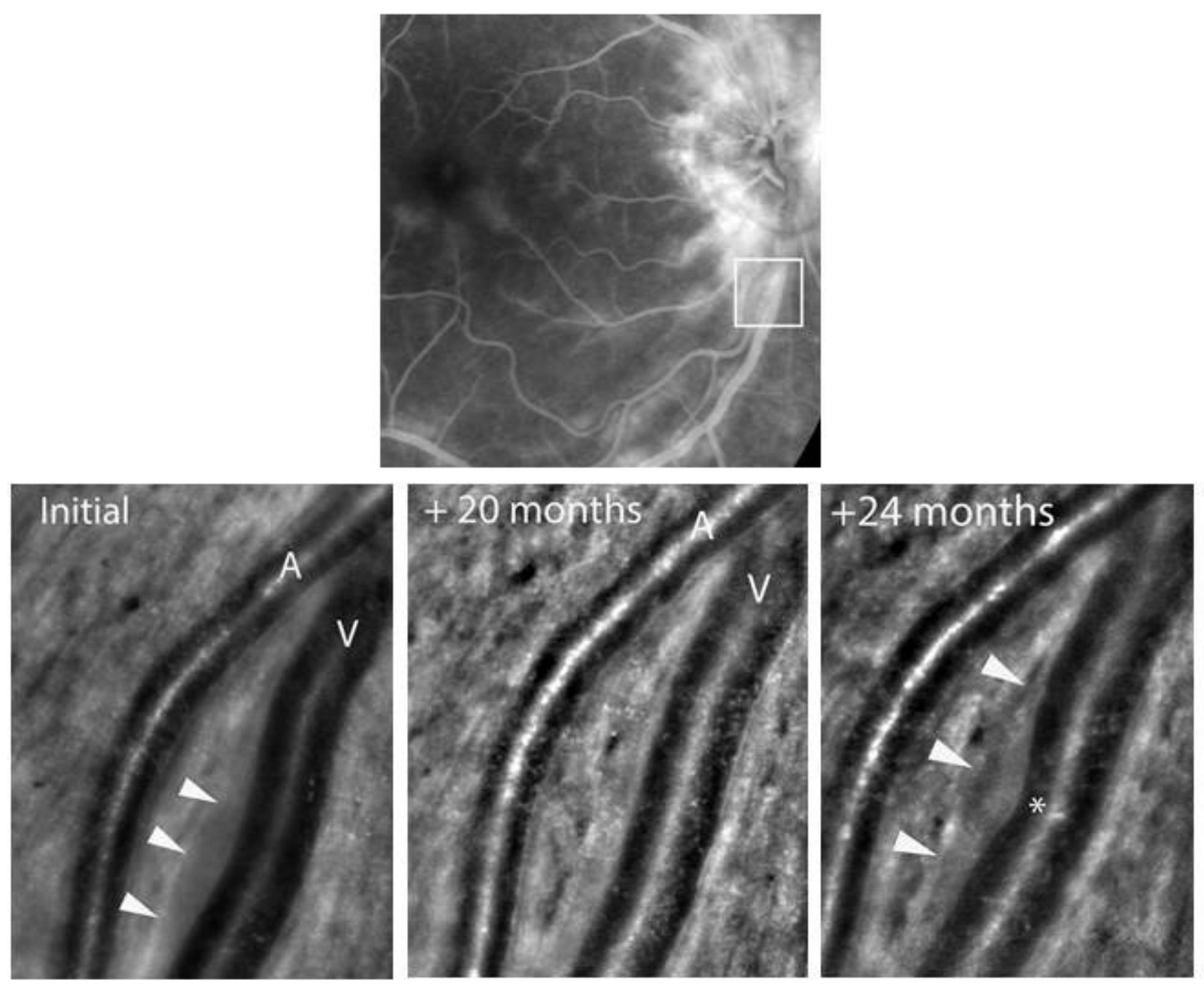


$D(\mu m)$

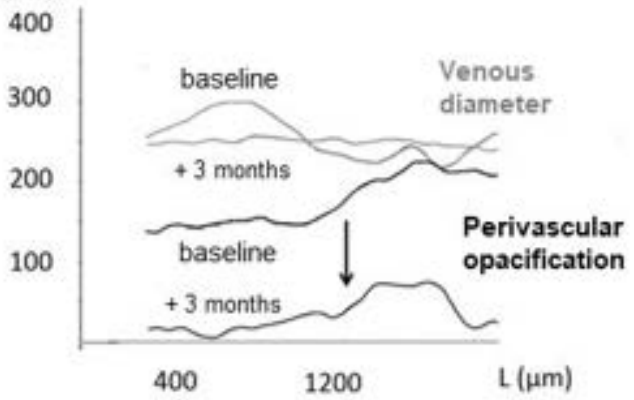


Width of venous diameters

Width of infiltrates

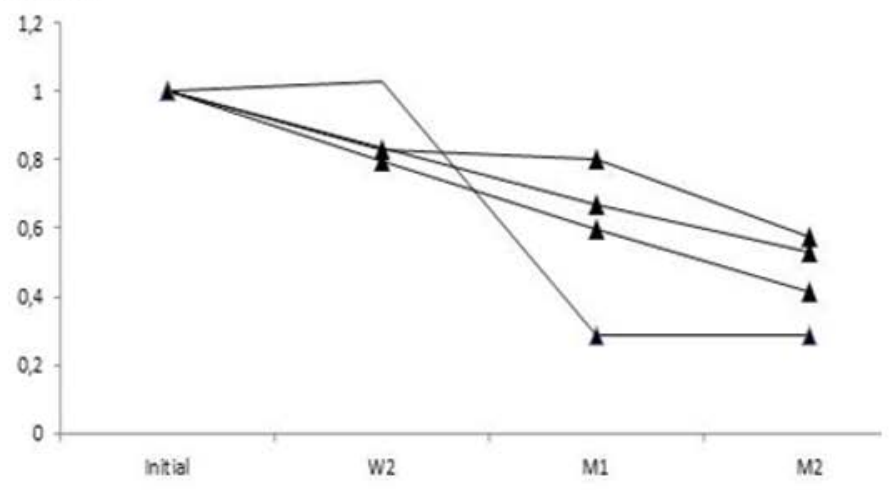

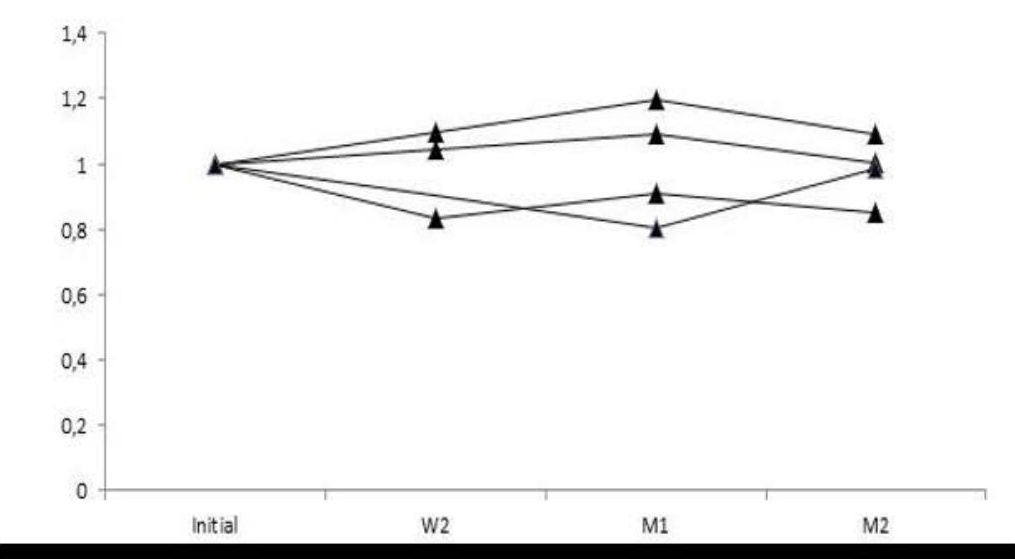




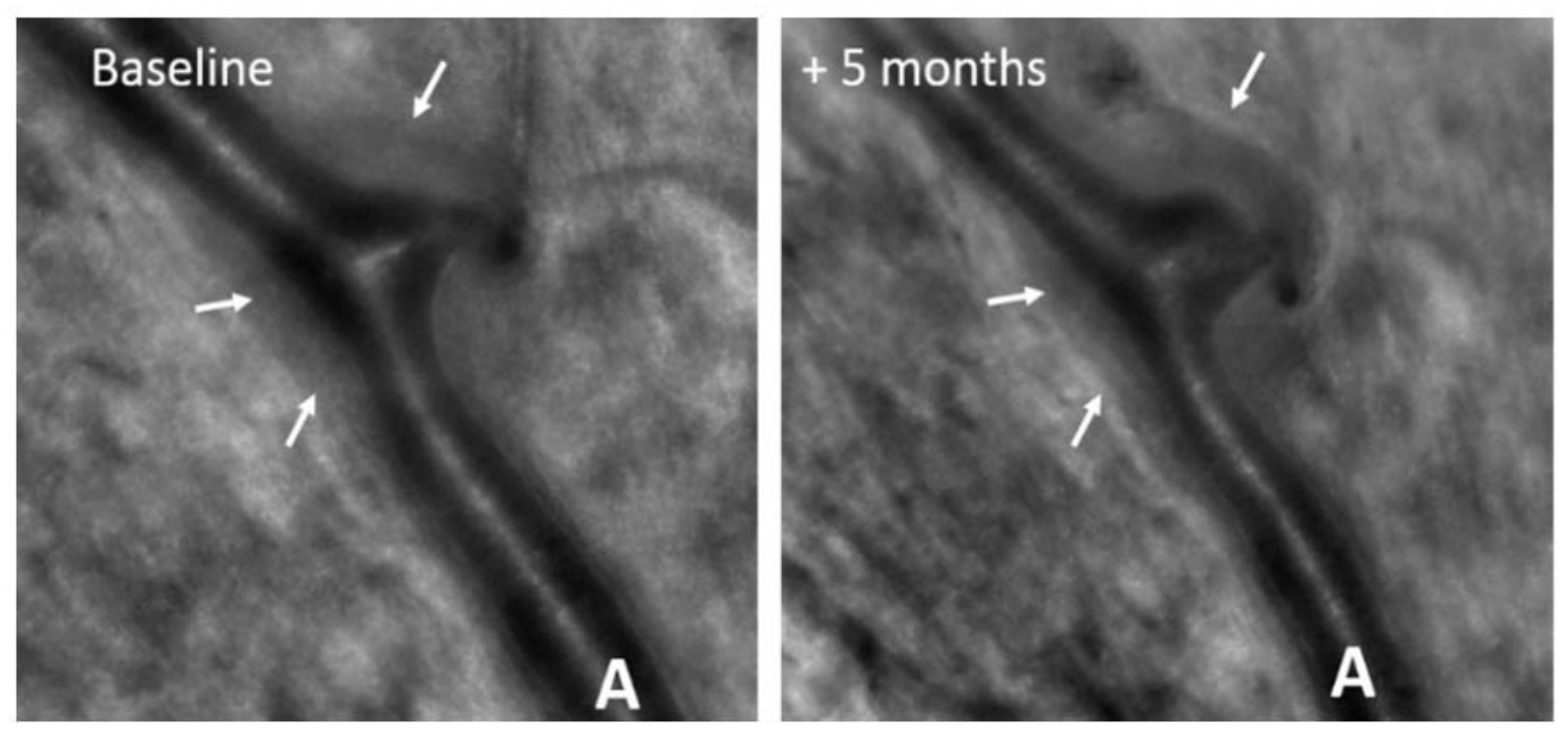




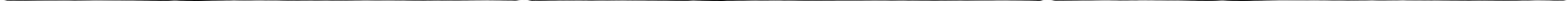




\begin{tabular}{|c|c|c|c|c|c|c|c|c|c|c|}
\hline Case & Age/sex & Diagnosis & $\begin{array}{l}\text { Duration } \\
\text { (months) }\end{array}$ & $\begin{array}{l}\text { Visual } \\
\text { acuity }\end{array}$ & $\begin{array}{c}\text { Peak } \\
\text { venous } \\
\text { sheathing } \\
\text { (diameter } \\
\mu \mathrm{m})\end{array}$ & treatment & evolution & $\begin{array}{l}\text { Maximal } \\
\text { venous } \\
\text { narrowing } \\
(\%)\end{array}$ & $\begin{array}{l}\text { Peak arterial } \\
\text { sheathing } \\
\text { (diameter) }\end{array}$ & $\begin{array}{l}\text { Maximal } \\
\text { arterial } \\
\text { narrowing } \\
(\%)\end{array}$ \\
\hline 1 & $65 / F$ & birdshot & 8 & $20 / 30$ & $+(90)$ & $\begin{array}{c}\text { PO prednisone } \\
+ \\
\text { mycophenolate } \\
\text { mofetil }\end{array}$ & relapse & $+(15)$ & none & none \\
\hline 2 & $26 / F$ & birdshot & 4.5 & $20 / 25$ & $+(35)$ & $\begin{array}{l}\text { PO prednisone } \\
+ \text { azathioprine }\end{array}$ & resolution & $+(5)$ & none & none \\
\hline 3 & $56 / F$ & birdshot & 8 & $20 / 40$ & $+(80)$ & $\begin{array}{c}\text { PO prednisone } \\
+ \\
\text { mycophenolate } \\
\text { mofetil }\end{array}$ & resolution & $+(20)$ & none & none \\
\hline 4 & $28 / F$ & toxoplasmosis & 1 & $20 / 32$ & $+(88)$ & $\begin{array}{c}\text { PO prednisone } \\
+\mathrm{PO} \\
\text { antibiotics }\end{array}$ & resolution & $+(4)$ & none & none \\
\hline 5 & $25 / F$ & toxoplasmosis & 2.5 & $20 / 32$ & $+(66)$ & $\begin{array}{c}\text { PO prednisone } \\
+\mathrm{PO} \\
\text { antibiotics }\end{array}$ & resolution & $+(4)$ & none & none \\
\hline 6 & $58 / \mathrm{M}$ & tuberculosis & 1 & $20 / 25$ & $+(90)$ & $\begin{array}{l}\text { PO prednisone } \\
+ \text { RIPE }\end{array}$ & resolution & NA & none & none \\
\hline 12 & $35 / M$ & tuberculosis & 3 & $20 / 32$ & $+(211)$ & $\begin{array}{l}\text { PO prednisone } \\
+ \text { RIPE }\end{array}$ & resolution & $+(15)$ & none & none \\
\hline 9 & $52 / \mathrm{M}$ & $\begin{array}{l}\text { Lyme } \\
\text { borreliosis }\end{array}$ & 12 & $20 / 40$ & $+(110)$ & $\begin{array}{c}\text { PO prednisone } \\
+ \\
\text { mycophenolate } \\
\text { mofetil }\end{array}$ & chronic & $+(20)$ & none & none \\
\hline 10 & $35 / \mathrm{M}$ & syphilis & 5 & $20 / 50$ & $+(45)$ & IV Penicillin & resolution & NA & none & none \\
\hline 7 & $35 / F$ & $\begin{array}{l}\text { multiple } \\
\text { sclerosis }\end{array}$ & 11 & $20 / 40$ & $+(99)$ & PO prednisone & resolution & $+(9)$ & none & none \\
\hline 8 & $44 / F$ & IRVAN & 4 & $20 / 20$ & $+(111)$ & None & chronic & $+(24)$ & $+(124)^{*}$ & NA \\
\hline 11 & $44 / F$ & idiopathic & 20 & $20 / 25$ & $+(225)$ & PO prednisone & resolution & $+(28)$ & $\begin{array}{c}+ \\
\text { (unavalaible) }\end{array}$ & $+(25)$ \\
\hline
\end{tabular}

Table 1. Clinical characteristics of patients (IRVAN: Idiopathic retinal arteritis, vasculitis, aneurysms and neuroretinitis). NA: not applicable. *arterial microaneurysm. 
